\title{
Coordination of Community-Based Activities for Older Adults and Family Members to Reduce Depression: A Case Study in Nong Khai, Thailand
}

\author{
Parichart Toomnan and Tanet Wattanakul \\ Faculty of Interdisciplinary Studies, Khon Kaen University, Thailand
}

\begin{abstract}
This study aims to decrease the depression of older adults in the Bo Hinn community, Nong Khai province and establish community's activities to promote social empathy based on Buddhism. The sample used consist of 20 older adults in in Bo Hinn community. The data were collected by various instruments and combined with a questionnaire for older adults. Ten community activities to reduce depression under the sufficiency economy philosophy and interviews about self-value perspectives after the participatory activities were conducted. Statistics of frequency and percentage were used for data analysis. Qualitative data was analyzed by using a content analysis.

Based on the research findings, it can be affirmed that the depression of older adults decreased after their participation. The sickness perception of older adults was reduced by 30 percent. The older adults had good family relationships in 95 percent of cases. The daily life routine of older adults was at 100 percent both before and after participation. However, it was found that the depression of older adults before the activities was low. In addition, it can be addressed that the number of older adults who had no depression increase from 25 percent to 50 percent.

Based on the interview, it can be revealed that the community activities accelerated the happiness due to the interaction with family members and other related people. The sample also reflected that not only the happiness but also decreased stress and more self-value led to the community pride.
\end{abstract}

Key words: Older adults, Community-based activities, Depression

\section{Introduction}

Country development both economicly and socially perspectives contribute to healthier people and longer lives. This phenomenon leads to both birth rate and death rate declines continuously. Thailand has been an aging society since 2005 based on the definition of an older adult number of 60 years for more than 10 percent or 65 years for more than 7 percent. For Thailand, it can be forecasted that in next 20 years it will be an aged society by considering more people of 60 years at more than 20 percent. Besides, it can be predicted that the number of more than 65 years will be over 14 percent. It can be affirmed that the number of older adults in Thailand will be 23.5 percent of the population in 2028 .

The family relationship problem can be considered as an essential problem contributing to other related problems for extended family members. Understanding can be regarded as effective medicine to heal and solve social problems. The specific topic under concern with older adults is a very essential issue to be studied due to the continuing increasing number of older adults every year. However, the important perspective that should not be ignored is their 
life experiences. This issue is normally ignored and is regarded as a family obstacle, i.e., taking care of older adults. Older adults can be considered as useful life experience keepers that can be used to solve problems occurring in next generations. Thailand is a strong Buddhist society. Buddhism is the national religion. Older adults always travel to the temples to do and enjoy cultural activities such as listening to the Buddhist teachings and dispensing water during in the Thai Songkran New Year festival. These events are a reflection of the traditional Thai society and culture and appear to be diminishing. Additionally, the perspective of current generations for older adults is as family burden. This situation reflects the rapidly changing Thai society.

Value measurement of human and natural resources based on both societal changes and the capitalism of the business environment causes social problems continuously. Empathy in the social and cultural system has disappeared. As a consequence, this current social problem needs to be focused upon and more attention under the rapid changes lead to the cultural human resources leakage in terms of physical and mental capacities. Older adults' problems in the past were more gradual and manageable because of large family members living together and the family priority of older adults' role for the next generations.

Thai society has currently altered from being an extended society to composed of nuclear families as well other the western culture adaptions without careful consideration has contributed to a somewhat emotionally harsh society. Older adults now are encountering difficulties in many aspects of life, for example, physical health, education background, daily activities, especially economics problems. They are in depression without the concern of family members leading to mental health problems and other related sickness.

There were many research projects about older adults' depression from 2007 to 2016 such as Depression in the Elderly with Diabetes (Suttisarn, 2007), osteoarthritis (Wiriyaong and Kespichayawattana, 2010), chronic disease (Yodkul and Srijakkot, 2012; Polyiam et al., 2014). Based on a study by Polyiam et al. (2014), it is revealed that there are many factors related to older adults' depression such as age, marital status, career or occupation and income sufficiency (Polyiam et al., 2014). Other factors can be regarded as level of sickness perspective, daily life and relationships with family members (Jitaree, 2014).

The national Development Plan covering approximately twenty years from 2017 to 2030 focuses on the enhancement of human resources development and building capacities via lifelong capacity development. Self-discipline, moral and ethical values, healthy environment and higher quality of life are included and targeted. Both economic and social development cannot happen from one group of citizens, but only from every group of citizens. Therefore, the older adults should not be ignored. Older adults can use their experiences to be tool for human resources and national economic and social development. As a result, there are community costs which can be established and utilized to create maximum benefits.

"Sufficiency Economy" is a philosophy conceived and developed by His Majesty King Bhumibol Adulyadej of Thailand (King Rama $9^{\text {th }}$ ). "Sufficiency economy" is a concept that is based on the foundation of Thai culture. It is a development approach based on the moderation, prudence, self-immunity as well as using knowledge and virtue. It is the basis for living. Most importantly, there must be "consciousness, wisdom and perseverance" which will lead to "happiness" in real life. It can be applied and suitable for people at all levels, from the family level, the community level, up to the state level both in the development and administration of the country in a middle way, especially regarding economic development. This philosophy also strengthens the mental foundation of the people in the nation especially government officials, theorists and businessmen at all levels to have an enhanced sense of morality and honesty. It also enables people to live with patience, perseverance, mindfulness, wisdom, and prudence to 


\section{4th International Conference on Future of Social Sciences 17-19 September 2021

be balanced and ready to handle rapid and extensive changes in terms of objects, society, environment and culture from global communities.

Nong Khai Province is one of special economic zones in to the national development agenda and in the ASEAN economy area. It seeks to enhance country development. This study which focuses on examining and solving older adults' depression is crucial and urgent. However, the research about older adults' depression in Nong Khai Province and the patterns of activities is limited. Therefore, the researchers desired to examine the older adults' depression in a community, Nong Khai Municipality, Nong Khai Province to analyse the problems and propose patterns of activities that can contribute to the decreasing of older adults' depression. Patterns of activities are designed by using the sufficiency economy of King Rama IX to develop older adults' capacities and strengthen communities promoting the country's security, prosperity and sustainability.

\subsection{Objectives}

1.2.1 To reduce the older adults' depression problems in Bo Hinn community, Nong Khai Municipality, Nong Khai Province.

1.2.2 To create and enhance activities in the community contributing to empathy in a Buddhist society.

\subsection{Expected benefits}

1.3.1 Older adults have less depressions.

1.3.2 Older adults have more self-value reflection.

1.3.3 Community offers more important perspectives to older adults.

\section{Research methodology}

\subsection{Sample}

Older adults in Bo Hinn community, Nong Khai Municipality, Nong Khai Province a total of 20 people.

\subsection{Research instruments}

Research instruments consist of various instruments as follows:

1. Depression Test is a questionnaire which was developed by Jitaree (2014). It consisted of 5 sections: 1) General Data; 2) Sickness Level Perception Test; 3) Family relationship questionnaire 4) Daily Routine Ability Test and 5) Depression Test

2. Community activities to reduce depression via sufficiency economy philosophy. Ten community activities were created to reduce depressive problems in the elderly by emphasizing the application of the Sufficiency Economy Philosophy under the royal initiative of His Majesty King Bhumibol Adulyadej the Great (Rama IX). For this research project, there are 10 community activities as follows.

1) Open Minds: This activity was carried out by a psychologist. Older adults were given

chances to express how they felt while participating in the activity.

2) Health Activities: It is a learning activity for self-health. This activity was run by a nurse

who has had more than 10 years experience giving advice to older adults.

3) Hearts Join Hearts Activities: It is an activity that allows older adults to have a chance to talk and exchange views and opinions with their family members. This activity was coordinated by volunteers and the research team.

4) Local Activities 1: Making Sandalwood Flowers 


\section{4th International Conference on Future of Social Sciences 17-19 September 2021

Actually, sandalwood flowers have been used in cremation ceremonies in Thailand since ancient days as it is believed that the fragrance of the wood will lead souls of the deceased to heaven. This activity was not only a simple thing that older adults can do but also allow them to contemplating death.

5) Local Activities 6: Ribbon Flowers for Giving Alms

According to Buddhism religious, Buddhists believe in making merit and doing good deeds in order to live happily. This activity allowed older adults to feel comfortable and make merit as well.

6) Local Activities 2: Making Dishwashing Liquid

The aim of this activity was to give the opportunity for elderly people and their family members to help each other and educate themselves

7) Local Activities 3: Herbal Liquid Balm

Thai elders' habit tend to carry inhalers with them at all times. These activities can help them to apply what they have learned in their daily life.

8) Local Activities 4: Bio-fermented Water

This activity enabled older adults to make use of community bio-fermentation for growing and nourishing trees and plants.

9) Local Activities 5: Compost from Waste Materials

This activity enabled older adults to use fertilizer to plant and nourish trees to thrive.

10) Local Activities 7: Friends Responding to Friends Activities

The objective of this activity was to encourage and give older adults the opportunity to talk and reflect on their opinions with other older adults.

3. Self-value interview after activities participation.

\subsection{Data Collection}

In the $1^{\text {st }}$ phase, the researcher team investigated to find out about older adults' problem characteristics in order to develop and design coordination of community-based activities, which comprised 10 activities for older adults and family members based on King Rama 9's economy sufficiency philosophy. In Phase 2, 10 Coordination of family's community-based activities were tried out with 20 older adults, 20 members of older adults and 10 villagers. This phase was carried out from 25 March 2019 to 4 April 2019. In the last phase, after having participated the activities, 15 older adults were asked in interviews how they felt toward those activities. The interview consisted of the 5 following questions:

- Did the older adults have more opportunities to talk with surrounding people after participating in the activities? How?

- Were the older adults able to use the activities participation to adjust to daily life in the community? How?

- Do the older adults smile more with family members and surrounding people? Why?

- Do the older adults desire the have additional activities at home or integrate with friends doing these activities? How?

- Do the older adults think that if there are more integration with friends, they will sell more products to earn extra incomes? How?

Finally, after the research project was completed, the researcher team visited Bo Hinn community to evaluate the project in November 2019.

\subsection{Quantitative data analysis}




\section{4th International Conference on Future of Social Sciences 17-19 September 2021 \\ Nice, France}

Extract data from the questionnaire was analyzed by using descriptive statistics to summarize and calculate frequency, percentage, mean and standard deviation to be presented in the tables.

Section 1 Personnel questionnaire consists of gender, age, marriage status, income, health problems and family characteristics.

Section 2 Sickness level perception test questionnaire developed by Jitaree (2014) adapted from the sickness level perception test of Rajcharak (2005). There are many criteria as follows.

3 means high sickness level perception

2 means moderate sickness level perception

1 means gradual sickness level perception

0 means no sickness perception

Section 3 Family relationship test by using questionnaire developed by Jitaree (2014) that is based on the conceptual framework of Friedman (1986) and Morrow and Wilson (1967, pp. 501-510). There are 16 questions in this test. The answers are in level of agreement as follows.

Absolutely agree means the message is totally consistent with feelings and reality.

Agree means the message is moderately consistent with feelings and reality.

Disagree means the message is slightly inconsistent with feelings and reality

Absolutely disagree means the message is totally inconsistent with feelings and reality.

Rating score is divided as follows.

Absolutely agree score is 4 .

Agree score is 3.

Disagree score is 2 .

Absolutely disagree score is 1 .

Score interpretation uses total score between 16 and 64 as follows.

38-64 means good family relationships.

27-37 means moderate family relationships.

16-26 means unfavorable family relationships.

Section 4 Daily routine ability test by using Barthel ADL Index that is translated into Thai by Jitapunkul et al. (1995). This test has 10 questions and the following criteria:

4.1 Walking and moving activity has 4 evaluation level as follows:

Level 0 means no ability.

Level 1 means high dependency assistance from others.

Level 2 means gradually increasing assistance from others.

Level 3 means that they can take care of themselves.

4.2 Having meal, getting dressed, excretion control, control of urinary excretion and

toilet usage. The evaluation score has 3 criteria as follows:

Level 0 means unable to do

Level 1 means gradual assistance needed from others

Level 2 means are able to take care of themselves

Score interpretation uses total score between 0 and 20 as follows:

0-8 means the older adults have a gradual ability to perform daily routines.

9-11 means the older adults have a moderate ability to perform daily routines.

12 means the older adults have a high ability to perform daily routines by themselves.

Section 5 Depression Test

The researcher used the depression test that was developed from Jitaree (2014) which is based on the Beck Depression Inventory: BDI (Beck et al., 1979) design by Beck and translated into Thai by Kumwalee (2002). Sirihorachai (2008: 84-87) revised the test by choice adjusting combined with Depression screening form at the Khon Kaen Rajanagarindra Psychiatric 
Hospital, Department of Mental Health, Ministry of Public Health (2003: 21). This test has 21 questions. The answers are in 4 levels as follows:

Always depressed means the message is always consistent with feelings.

Often depressed means the message is often consistent with feelings.

Sometimes depressed means the message is sometimes consistent with feelings.

No depression means the message is inconsistent with feelings.

The scoring can be shown as follows.

Never depressed is 0 .

Depressed sometimes is 1 .

Often depressed is 2 .

Always depressed is 3 .

Score interpretation uses total score between 0 and 63 as follows.

0-13 means no depression.

14-20 means minor depression.

21-26 means moderate depression.

27 or more than 27 means high depression.

\subsection{Qualitative data analysis}

Content analysis was used to undertake this process.

\section{Results}

Section 1: Overall data of older adults

TABLE 1: Number and percentage of sample $(n=20)$

\begin{tabular}{lcc}
\hline Individual factors & Number & Percentage \\
\hline Gender & 8 & 40 \\
Male & 12 & 60 \\
Female & 13 & 65 \\
Age (Years) & 6 & 30 \\
$60-69$ & 1 & 5 \\
$70-79$ & & \\
80 or over & - & - \\
Marriage status & 13 & 65 \\
Single & 7 & 35 \\
Marriage & & 10 \\
Divorced/Widowed/Separated & 2 & 10 \\
Education level & 2 & 60 \\
Not educated & 12 & 10 \\
Not graduate primary school & 2 & 10 \\
Graduate primary school & Number & Percentage \\
Graduate secondary school & 2 & - \\
\hline Individual factors & - & 80 \\
\hline Graduate certificate or diploma & & 15 \\
Graduate bachelor or higher than bachelor degree & 16 & 5 \\
Average income per month & 3 & \\
Less than 5,000 Baht/Month & 1 & \\
5,001-10,000 Baht/Month & & \\
More than 10,001 Baht/Month & & \\
Income sources & & \\
\hline
\end{tabular}




\begin{tabular}{lcc} 
Son and daughter & 9 & 45 \\
Cousin & 1 & 5 \\
Rent & 1 & 5 \\
Pension & 3 & 15 \\
Self-employment & 6 & 30 \\
Others & - & \\
Career & & 55 \\
No career & 11 & 25 \\
Freelance & 5 & 5 \\
Commercial & 1 & 15 \\
Farmers & 3 & \\
Family & & 70 \\
Single family & 14 & 30 \\
Extended family & 6 & \\
\hline
\end{tabular}

From table 1, it can be described that most of older adults are female at 60 percent and with the age level between 60 and 69 years for 65 percent. Most of older adults are married at 65 percent. Older adults are widows, divorced and separate for 35 percent. Older adults graduated primary school at 60 percent. Older adults have average income less than 5,000 baht per month at 80 percent. Income source of older adults comes from sons and daughters at 45 percent. Most of older adults had no career at 55 percent. Older adults have single families at 70 percent.

\section{Section 2 Sickness level perception}

Table 2 Number and percentage of sample classified by sickness level perception

\begin{tabular}{lccccc}
\hline \multirow{2}{*}{ Sickness level perception } & \multicolumn{2}{c}{$\begin{array}{c}\text { Before attending } \\
\text { the workshop }\end{array}$} & $\begin{array}{c}\text { After attending } \\
\text { the workshop }\end{array}$ \\
\cline { 2 - 5 } & Number & Percentage & Number & Percentage \\
\hline High level & - & - & - & - \\
Moderate level & $\mathbf{9}$ & $\mathbf{4 5}$ & $\mathbf{7}$ & 35 \\
Gradual level & $\mathbf{1 1}$ & $\mathbf{5 5}$ & $\mathbf{7}$ & 35 \\
Not serious & - & - & $\mathbf{6}$ & 30 \\
\hline
\end{tabular}

From table 2, it can be explained that the sickness level perception of sample before attending the activities is gradual at 55 percent. The sickness level perception of sample after attending the activities is moderate at 35 percent. The sickness level perceptions of sample is no sickness after attending the activities at 30 percent.

Section 3 Family relationship

Table 3 Number and percentage of sample classified by family relationship $(n=20)$

\begin{tabular}{lcccc}
\hline \multirow{2}{*}{ Family relationship level } & \multicolumn{2}{c}{$\begin{array}{c}\text { Before attending } \\
\text { the workshop }\end{array}$} & \multicolumn{2}{c}{$\begin{array}{c}\text { After attending } \\
\text { the workshop }\end{array}$} \\
\cline { 2 - 5 } & Number & Percentage & Number & Percentage \\
\hline Good & 9 & 45 & 19 & 95 \\
Moderate & 11 & 55 & 1 & 5 \\
Not good & - & - & - & - \\
\hline
\end{tabular}


From table 3, it can be revealed that the older adults have moderate family relationships before attending the activities. The family relationship is good at 95 percent and moderate at 5 percent after attending the activities.

Section 4 Daily life routine capacity

Table 4 Number and percentage of sample classified by daily life routine $(n=20)$

\begin{tabular}{lcccc}
\hline \multirow{2}{*}{ Daily life routine capacity } & \multicolumn{2}{c}{$\begin{array}{c}\text { Before attending } \\
\text { the workshop }\end{array}$} & \multicolumn{2}{c}{$\begin{array}{c}\text { After attending } \\
\text { the workshop }\end{array}$} \\
\cline { 2 - 5 } & Number & Percentage & Number & Percentage \\
\hline High & 20 & 100 & 20 & 100 \\
Moderate & - & - & - & - \\
Gradual & - & - & - & - \\
\hline
\end{tabular}

From table 4, it can be explained that the sample has a high daily routine capacity at 100 percent both before and after attending the activities.

Section 5 Older adults' depression

Table 5 Number and percentage of sample classified by older adults' depression $(n=20)$

\begin{tabular}{lcccc}
\hline \multicolumn{1}{c}{ Depression level } & \multicolumn{2}{c}{$\begin{array}{c}\text { Before attending } \\
\text { the workshop }\end{array}$} & \multicolumn{2}{c}{$\begin{array}{c}\text { After attending } \\
\text { the workshop }\end{array}$} \\
\cline { 2 - 5 } & Number & Percentage & Number & Percentage \\
\hline No depression & $\mathbf{5}$ & $\mathbf{2 5}$ & $\mathbf{1 0}$ & $\mathbf{5 0}$ \\
Low depression & $\mathbf{1 1}$ & $\mathbf{5 5}$ & $\mathbf{9}$ & $\mathbf{4 5}$ \\
Moderate depression & $\mathbf{4}$ & $\mathbf{2 0}$ & $\mathbf{1}$ & $\mathbf{5}$ \\
High depression & - & - & - & - \\
\hline
\end{tabular}

From table 5, there were no older adults with a high depression level both before and after the training. Most of them has low depression at 55 percent before training and 45 percent after training. By comparing with the percentage of older adults that has no depression before and after training, it was found that the percentage of older adults that had no depression increased from 25 percent to 50 percent. Five percent of the older adults that had moderate depression after the training.

\section{activities \\ Interview about self-value reflection of older adults after participating in the}

This research establishes community activities to reduce depression by using sufficiency economy philosophy consisting of 10 activities. The researcher interviewed 15 older adults out of the 20 after attending the activities. The interview was combined with 5 questions that can be summarized as follows:

1) Can older adults comfortable talk to surrounding people easier? How?

All older adults explain that they have more chance to talk with family members and surrounding people to promote happiness and decrease stress. They also confirm that the activities have benefits, create more knowledge and offer brainstorming.

2) Can older adult use the training activities in daily life or in community? How?

All the older adults confirm that they can use the training activities in daily life or in community. The activities are good and beneficial. They also propose that training activities reduce family expenditures and are easier to learn and practice at home such as using dish wash liquid and soap. 


\section{4th International Conference on Future of Social Sciences 17-19 September 2021 \\ Nice, France}

3) Do older adults feel more apt to smile with family members? Why?

All older adults confirm that they feel more likely to smile with family members and surrounding people. They describe the reasons that activities give everyone more opportunities to talk together. They also talk about the participatory activities with family members and neighbors to reduce stress and foster more smiling and happiness. Some older adults claim that activities participation makes them feel less lonely and less depressed.

4) Do older adults find other activities to implement at home or with friends? How?

All older adults were interested in and desiring to find other activities to implement at home or with friends. They describe that it presents more opportunities to talk and brainstorm leading to knowing each other more and reducing stress. Some older adults explain that additional activities create more family income. Nevertheless, some older adults have time limitations, work and health problems. Some older adults propose exercise activities for healthiness.

5) Do older adults agree to sell merchandise after integration for more income? Are older adults interested in participating? How?

All older adults agreed with this proposal. This answer reflects the previous perspective of the above question that integration makes them feel less lonely, enjoying life more with less assistance. Furthermore, they confirm their interest in participating in future projects.

\section{Discussion}

\section{1 Depression of the older adults in the Bo Hinn Community, Nong Khai Municipality, Nong Khai Province}

From the research findings, it can be revealed that the sickness perception level of the older adults decreased from gradual to moderate. The sickness perception level of older adults is no pain to gradual after participating in the activities. Additionally, it is found that the older adults have higher capacity in doing daily routines. The very essential findings cover better family relationships between older adults and family members after attending the activities. The amount of reported depression in older adults decreased compared to that before participation in the activities at 25 and 50 percent. After participating in the activities those having no depression was 50 percent. These findings affirm that the seminar activities reduce the depression levels of older adults which is consistent with Jitaree (2014). It is revealed that the sickness level perception, capacity for doing daily routines and family relationship can be regarded as predictive factors in older adults' depression. In addition, Kabkumba and Rungreaungkulkij(2014) also found that the continuing role of activities participation of older adults is necessary for depression reduction. Consequently, the appropriate activities establishment is a consideration that must not being ignored. In previous years there has been much research of older adults such as Intamuen and Suppapitiporn (2013), Charoenphaet and Choowattanapakorn (2016) and Bunloet (2016). These research works explored the relationship between activities participation and older adult's depression. The research results confirm that the activities participation leads to older adults' depression levels decreasing such as Imsompoch (2006) and Kanungpiarn and Salavatanakul (2019). These researchers examined music and art activities to heal older adults' depression. It is concluded that the depression of older adults decreases after obtaining the music and art theraphy. Moreover, Bunloet (2016) studied about factors related to depression of elderly people with chronic diseases. It is found that the prevalence rate of depression among the elderly with chronic diseases in the community in the triangular primary care center was quite high. It was found in 


\section{4th International Conference on Future of Social Sciences 17-19 September 2021 \\ Nice, France}

one-third of the elderly were afflicted with chronic disease. Factors relate to depression are the sufficiency of income and the frequency of social activities participations.

The researcher team also interviewed older adults after activities participation. The older adults confirm that the activities participation leads to happiness, reduces loneliness, and give more chances to talk with family members and surrounding people as well as relaxing due to do not being loneliness.

Furthermore, the researcher team explored self-value reflection of older adults. The older adults were interviewed after participating in the activities. It is revealed that all older adults have self-value reflection. They affirmed that the integration to do activities reduces loneliness, and is enjoyable and relaxing. One can gain knowledge and generate extra incomes. They feel very proud that they are able to take care of themselves and family which is consistent with Imsompoch (2006), Pikun (2014), Jitaree (2014), and Puttametta and Soonthornchaiya (2 0116$)$. It is found that the activities participation contributes to not only older adult's depression reduction but also more self-value reflection.

\subsection{Decreasing depression by using community activities based on the sufficiency economy philosophy}

The sufficiency economy philosophy was one crucial intention of King Rama IX. The essential concept is about the way of living of all citizens in the kingdom. This concept is based on Thai culture. Other important aspects are moderate way of living, consciousness, sufficiency, reasoning, self-immunization as well as knowledge and morality. Consciousness, intelligence and devotion are the ways leading to true happiness in life.

The research team used the sufficiency economy philosophy of King Rama IX to conduct this research via activity pattern design. All project participants explained that seminar activity is good and useful. Moreover, the seminar activity can be adapted for use in daily life and reduce household expenditures.

From the research result above, it can be addressed that it is consistent with Pholprasert and Witayathawornwong (2016) and Sudsomboon et al. (2016). It can be concluded that the older adults who learn self-caring based on sufficiency economy philosophy have more knowledge and understanding than the older adults who do not learn this curriculum. Recently, Jullamate et al. (2018) studied the development of a rehabilitation model for the chronically ill older adults through family and community participation (based on the concept of sufficiency economy from Thai wisdom) by using family and community participation based on sufficiency economy philosophy and Thai wisdom. There are six procedures proposed as follows 1 ) Older adults caring policies by community executives and leaders 2) Cooperative planning by the cooperation of people who are responsible for the older adults' caring 3 ) Planning and implementation by people in the community who are responsible for the older adults recovery 4) Evaluation of the older adults recovery by older adults, family, community leaders, public health volunteers and nurses 5) Older adults recovery monitoring and feedback information by public health volunteers, community leaders and nurses to older adults and families and 6) Effective older adults recovery management via municipality consisting of sickness information management and the recovery needs of each older adult, management of related people and necessary recovery equipment support.

\section{Project monitoring and evaluation}

The research team analyzed the data after implement training for older adults, family members and people in Bo Hinn, Nong Khai Municipality, Nong Khai Province from 25 March 


\section{4th International Conference on Future of Social Sciences 17-19 September 2021 \\ Nice, France}

2019 to 4 April 2019. Both quantitative and qualitative data analysis were adopted. The research team also monitored and evaluated the project via site visits to interview 10 older adults from 31 October to 2 November 2019. The monitoring and evaluating results can be summarized as follows:

Older adults confirm that they are healthy both physically and mentally. They can do daily life routines. They feel more self-value reflection after participating in the activities. They have more chances to talk with family members and improve family relationships. They have more knowledge to create household equipment that can reduce expenditures. Some hobbies can be an extra source of income. They confirm that this training project has benefits. They can gain knowledge to adapt in daily life. They desire to attend the activities next time. They propose other activities such as exercise and relaxing muscle massage.

\section{Suggestions}

\subsection{Suggestions from the results of this study}

1) Older adults and family members should pay more attention and importance to doing activities together and to take care of each other both physically and mentally.

2) Older adults should talk and exchange ideas about self-caring with others or create older adult groups to share experiences and decrease stress.

3) Older adults should obtain and transform knowledge to adapt to daily life to reduce family expenditures and create extra income for the family.

4) Older adults should take depression reduction activities based on the sufficiency economy philosophy adapted to household and community as well as to other interested communities.

5) Encourage older adults who use stress reduction medicine to use it less.

\subsection{Suggestions for further studies}

1) The activities can create more opportunities to do things together with older adults, family members and neighbors. These activities should be able to create extra family income and practice in daily life. These activities should be based on the sufficiency economy

philosophy and take various forms such as almsgiving with ribbon-flowers, dish liquid washer,

soap, bakery and relaxing muscle massage.

2 ) Activities that can provide knowledge to older adults, family members and neighbors should be implemented. The topics should cover self-caring, exercising, nutrition including physical and mental health caring. Buddhism teachings can be used as useful guidelines for daily life to decrease depression for all ages particularly for older adults, thus preventing mental illnesses.

3 ) The research findings can be extended and implemented in terms of human resources coaching curriculum development and elaborate knowledge to reduce the depression of older adults, family members and other people who are interested in this issue.

\section{References}

Beck, A.T.,Rush, A.J. Shaw,B., \& Emery, G. (1979). Cognitive therapy of depression. New York: Guilford Press.

Bunloet, A. (2016). Prevalence and factors associated with depression among the elderly community resedents with chronic diseases in Samliam Urban Primary Care Unit, Khon Kaen. Srinagarind Medical Journal, 31(1): 16-24.

Charoenphaet, P. and Choowattanapakorn, T. (2016). Impact of Co-Application of Music Therapy and Social Support on Depression in Elderly Parkinson's Disease Patients 
Department of Mental Health, Ministry of Public Health and the Psychiatric Association of Thailand. (2003). Psychiatric and Mental Health Nursing Practice Standards 2. Bangkok: Thammasat University Printing.

Friedman,M.M. (1986). Family nursing:Theory and assessment. New York, Appiton-Century Craftes.

Imsompoch, Q. (2006). The effect of therapeutic art on self-esteem of the elderly in Bangkae home. Master of Science, Chulalongkorn University.

Intamuen N, Suppapitiporn S. (2013). Effect of therapeutic arts in the elderly with mild to moderate depression. Chula Med J ,57(6): 751 - 63.

Jitapunkul, S., Horbunlerkit, T., Kamolratanakul, P., and Suteparuk, S. (1995). Factors associated with dependency status of the elderly living in Thamprakorn Home Care for the elderly. Chulalongkorn Medical Journal, 39(10): 733-741.

Jitaree, B. (2012). The factors influencing depression amongst the elderly at a community in Nakhon Pathom Province. Department of Community Nurse Practitioner, Christian University of Thailand.

Jullamate, P. , Subgranon R., , Karuna, S., Noimontree, W., and Sungworawongpana, N. (2018). The development of a rehabilitation model for chronically ill older adults through family and community participation (based on the concept of sufficiency economy from Thai wisdom). Burapha Journal of Medicine, 5(2): 25-37.

Kabkumba C. and Rungreangkulkij, S. (2014). Social support factor and depression in elderly: The difference between women and men. Journal of Nursing Science \& Health, 37(2), 71-81.

Kanungpiarn, T. and Salavatanakul, S. (2019). Effect of Mozart music for capability memory in elderly. Journal of Preventive Medicine Association of Thailand, 9(3): 390400.

Kumwalee, S. (2002). Experimental implementation of Beck', s cognitive counseling program for depression reduction among HIV patients at the Nanglerng Region 1 Venereal Disease and AIDS Control Center. Faculty of Liberal Arts, Thammasat University.

Morrow, W. R., \& Wilson, R. C. (1961). Family relation of bright high-achieving and under achieving high school boy. Child Development,32, 501-510.

Pikun, L. (2014). The relationship between self esteem and depression of elderly the area of responsibility of health promoting Tambon Hositals, Sriracha District Chonburi Province. Faculty of Public Health, Burapha University.

Pholprasert, P. and Witayathawornwong, P. (2016). The Effectiveness of the Process of Developing the Life Quality of the Elderly under the Sufficiency Economy: A Case Study Lom Kao District, Phetchabun Province. Journal of Preventive Medicine Association of Thailand, 6(3): 240-255.

Polyiam, I., Siri, S., Taechabunsermsak, T., and Sujirarat, D. (2014). Prevalence and Associated Factors of Depression in Elderly Patients with Non Communicable Disease, Roi Et province. Graduate Research Conference, Khon Kaen University, 1848-1854.

Puttametta, M. and Soonthornchaiya, R. (2016). Selected factors related to depression of the older persons with depressive disorder in the central region. The Journal of Psychiatr and Mental Health, 30(2): 69-82.

Rajcharak, B. (2005). Family relatioshkip, perceived severity of illness, activities of daily living and anxiety of hospitalized elders in Nakhon Si Thammarat Province. Faculty of Nursing, Prince of Songkla University. 


\section{4th International Conference on Future of Social Sciences 17-19 September 2021

Sirihorachai, R. (2008). Experimental implementation of Beck's cognitive counseling program for depression reduction among the elderly at nursing homes: a case study at Bangkhae Nursing Home. Faculty of Liberal Arts, Thammasat University.

Sudsomboon, S., Hemchayart, A., Kaenla, P., and Sudsomboon, S. (2016). Development of self-care courses for the elderly according to the Sufficiency Economy Philosophy. Health Systems Research Institute.

Suttisarn, P. (2007). Depression and context of life of diabetes mellitus patients in diabetes mellitus cline, Khong Khai Hopital. Master of Public Health, Chiang Mai University

Yodkul, S. and Srijakkot, J. (2012). Predictive factors of depression among older people with chronic disease in Buriram Hospital. Journal of Nurses' Association of Thailand, North-Eastern Division, 30(3): 50-57.

Wiriyaong and Kespichayawattana, 2010). Selected factors related to depression in older persons with knee osteoarthritis. 